\title{
Acoustic and Thermal Insulation of Nanocomposites for Building Material
}

\author{
Shanaz, Hussein Ahmad ${ }^{1 *}$ \\ Rana Mahdi Salih ${ }^{2}$ \\ Received 30/1/2019, Accepted 16/7/2019, Published 1/6/2020

@.

\begin{abstract}
:
This work aims to enhance acoustic and thermal insulation properties for polymeric composite by adding nanoclay and rock wool as reinforcement materials with different rations. A polymer blend of (epoxy+ polyester) as matrix materials was used. The Hand lay-up technique was used to manufacture the castings. Epoxy and polyester were mixed at different weight ratios involving (50:50, 60:40, 70:30, 80:20, and 90:10) wt. \% of (epoxy: polyester) wt. \% respectively. Impact tests for optimum sample (OMR), caustic and thermal insulation tests were performed. Nano clay (Kaolinite) with ratios ( 5 and $7.5 \%$ ) wt.\%, also hybrid reinforcement materials involving (Kaolite $5 \& 7.5 \%$ wt. $\%+10 \%$ volume fraction of rockwool ) were added as reinforcement materials to the optimum sample. Results of impact test prove that the optimum sample has (80:20) wt. \% of mixing ratio of (epoxy: polyester) wt. \% for using as matrix materials. Moreover, the adding of nanoclay (Kaolinite) with ratio ( $7.5 \mathrm{wt} . \%)$ leads to the highest sound insulation. The sound intensity started at (99.8) db at $100 \mathrm{~Hz}$, and reached to (101.3) db at $10000 \mathrm{~Hz}$., which is much lower than the values obtained from the un-reinforced blend, of which the sound intensity started at (107.2) db and reached to $(108.7) \mathrm{db}$., at the same range of frequencies. Thermal conductivity results show that the optimum matrix with $(7.5 \%)$ wt. \% has the lowest value about $(0.443 \mathrm{k} . w \backslash \mathrm{m} . c)$.
\end{abstract}

Key words: Acoustic insulation, Nano clays, Nanocomposite, Polymer blends, Thermal insulation.

\section{Introduction:}

Nano composites development is an innovative approach to the manufacturing of composite materials without changing polymer composition. To the contrary of traditional filler, nanocomposites are reinforced with nano-scale fillers, dispersed more evenly throughout the matrix. The changing from micro-or macro-scale reinforcement to nanoscal the change from micro-, or macro-, scale reinforcement to nano scale reinforcement, gives a wider range of properties, which are not usually obtained using large scale additions, for instance: heat and sound insulation are affected by these additives, to a greater extent than when using micro-, or macro- scale additives. In the last decade, a growing attention was directed toward nanotechnolpgy and its application and a great academic and industrial interest was committed to the development of these innovative materials. (1).

${ }^{\mathrm{T}}$ Materials Science Branch, Department of Applied Sciences, University of Technology, Baghdad, Iraq.

${ }^{2}$ Applied Sciences Research Unit, Department of Applied Sciences, University of Technology, Baghdad, Iraq. ${ }^{*}$ Corresponding author: shanaz.husien@ gmail.com *ORCID ID: https://orcid.org/0000-0001-6996-8130
Noise is considered a main pollutant to the environment, generating mainly from the daily activities of modern society (transportation, industries and other urban activities). Excessive exposure to noise can induce negative effects on human hearing ability, high blood pressure, tinnitus, psychological and sleep disorders(2). Polymers generally have low intrinsic thermal conductivity when compared to metals and ceramics, making them ideal for use in the manufacture of heat and sound insulators, and foamed polymers have been used in this field for decades. Even in high technology applications, like encapsulation and electronic packaging, satellites, polymers have been used in insulation, since they combine low conductivity together with light weight and low thermal expansion. This technology has been enhanced using the concept of composite materials, where fillers are added to polymers to gain further properties, usually not obtainable by polymers alone. (3)

As a rule, when a polymer material is set to be thermally insulating, an over-all methodology to investigate its suitability for this application is required. i.e., it is not only a matter of choosing the constituent materials, but the means by which the 
resulting material is tested before being put in to actual usage in real life must be well-studied. So, not only thermal and sound insulation should be studied, but other accompanying properties (mechanical, chemical or processed) should be taken in to account. (4)

Guzel Kaya. et. al.(5) studied the synthesis of silica xerogel (Silicon dioxide manufactured for treatment of difficult to stabilize beers) the sol-gel technique was used to dry the ash, using xerogel $(0.5,1.0$ and $1.5 \mathrm{wt} \%)$ as an addition to epoxy, which was used as a matrix. From the materials mentioned above, an epoxylsilica (xeorgel) nanocomposite materials casting was prepared, in which all of them have shown uniform distribution of xerogel silica in epoxy, except the one with $1.5 \mathrm{wt} \%$. The resulting nanocomposite had low density, accompanied by good stability and low conductivity at high temperature, the specimen with $1.5 \% \mathrm{wt}$ silica xerogel had thermal conductivity value $(0.220)$ $\mathrm{W} \backslash \mathrm{mK}$.The same composite material was put to test the same insulation properties, which were found to decrease at high ratio of silica xerogel. The unreinforced epoxy had the highest value of under absorption than the composites. The researcher found that the manufactured composites developed heat and sound insulation than the conventional high cost, and the eco-aggressive materials. (5)

Burattia. et. al. (6) studied capabilities of using recycled materials with high sustainability as possible thermal insulation materials in building envelopes. The researcher chose basalt-based panels to accomplish their work. Furthermore, the sound insulation was investigated using kundts tube. The materials proved to have superior properties compared to traditional insulating materials; nevertheless, they showed less favorable mechanical strength. However, the resulting material could be used for refurbishment applications. (6)

Lee1. et. al.(7) manufactured a composite of carbon nano tube (CNT)as a reinforcement for a polymer matrix Acrylonitrite Butadien styrene (ABS), and studied its sound proofing qualities. The results proved that the addition of CNT decreased the sound transmission by $15 \%$ compaed to its level for the unreinforced specimen, both at frequency $3400 \mathrm{H}$, and this may be attributed to the increased stiffness of the composite specimen.

The aim of research is to improve sound insulation by adding CNT. (7)

The research attempts to manufacture a material that combines good acoustic and thermal insulation with mechanical durability, together with a reasonable cost of the constituent materials. i.e. the matrix is (epoxy+ polyester) blend, with a reduced cost, and nano clay used as a reinforcement, is hybridized with a low-weight, cost effective rock wool, to improve thermal and sound insulation.

\section{Material and Methods: \\ Materials}

\section{Unsaturated Polyester (UP)}

Clear, thermoset polymer, which solidifies with the addition of hardening agent (methyl ethyl ketome peroxide-MEKP) in weight ratio (1)\%, the (UP) was provided by Saudi Industrial Resins Limited Company $(\mathrm{SIR})^{\mathrm{TM}}$. Properties are shown in Table 1

Table 1. polyester properties

\begin{tabular}{ll}
\hline Density & 1 to $1.3 \mathrm{~g} \backslash \mathrm{cm}^{3}\left[25^{\circ} \mathrm{C}\right]$ \\
\hline Flash point & 30 to $33^{\circ} \mathrm{C}$ \\
Physical state & Liquid [clear] \\
Viscosity & Dynamic: $400 \quad$ to 600 \\
& Mpas (400 to $600 \mathrm{CP})$ \\
Solubility & Insoluble in cold water \\
\hline
\end{tabular}

\section{Epoxy Resin}

Epoxy resin that is used in this work was Sikadur - 105, manufactured by Sika ${ }^{\mathrm{TM}}$, which comes as a two-component translucid, pale yellow liquid, that changes upon mixing with the hardener in to a solid.(epoxylhardener) system is mixed in a ratio of $3: 1$ of both of them respectively. The properties of epoxy are shown in Table 2

Table 2. general properties of epoxy resin.

\begin{tabular}{lll}
\hline Flexural properties & 14 day $7900 \mathrm{psi}(54 \mathrm{MPa})$ \\
\hline Viscosity (mixed) & $200 \mathrm{cps}$ & \\
Pot life & 30 minutes.(60 gm mass) \\
Tensile properties & 14 day 4500 psi(37.2 \\
& $\mathrm{MPa})$ & \\
& $54 \mathrm{MPa}$ & \\
14 day tensile strength & $3.1 \%$ \\
Elongation at break & $1400 \mathrm{MPa}$ \\
Modulus of elasticity & \\
\hline
\end{tabular}

\section{Nanoclay (Kaolinite)}

Kaolinite is known for its abundance and desired properties, leading to its use in a wide range of plastics, cements and catalysts. The nano clay used in this study was provided by Intelligent Materials Pvt.Ltd. TM. Properties are shown in Table 3.

Table 3. general properties of nanoclay.

\begin{tabular}{ll}
\hline Molecular weight & $258.2 \mathrm{~g} / \mathrm{mol}$. \\
\hline Appearance & White powder \\
Specific gravity & $\sim 2.6$ \\
Melting point & $>1500{ }^{\circ} \mathrm{C}$ \\
Solubility & Insoluble in cold water \\
\hline
\end{tabular}




\section{Rockwool:}

Sometimes called stone wool, is a type of inorganic fiber. The loose rockwool used in this study was manufactured by Saudi Rockwool $^{\mathrm{TM}}$. It is primarily used for heat and sound purposes, wherever needed in industrial and constructional applications, e.g. Air conditioning systems in buildings and transpiration applications. In addition to its unique properties which make it useful as an insulator, its mechanical properties make it beneficial in high tensile strength application, together with chemical and thermal. Table 4 shows the general properties of rockwool.

Table 4. general properties of rockwool.

\begin{tabular}{ll}
\hline Designated use & $\begin{array}{l}\text { Loose filler for heaters e, ovens, } \\
\text { cookers, and for brake pads }\end{array}$ \\
\hline Desired properties & $\begin{array}{l}\text { Reduction of transferred heat, } \\
\text { and transmitted noise. } \\
\text { Appearance }\end{array}$ \\
Macking & Loose black and yellow \\
\hline
\end{tabular}

\section{Method:}

Hand lay-up method was used to prepare samples with mold size of $\left(250 \mathrm{~mm}^{*} 250 \mathrm{~mm}\right)$. Unsaturated polyester was mixed with epoxy to form a blend. Five different percentages of epoxy and polyester were mixed, starting from $(90: 10) \%$, $(80: 20) \%, \quad(70: 30) \%, \quad(60: 40) \%$, of epoxy and polyester respectively, and reaching (50:50)\% of both. The optimum mixing ratio (OMR) was decided upon the results of the impact test carried out on blends of the above mentioned percentages. The (80:20)\% has shown the highest impact strength value, hence selected as a matrix to the composite, which was reinforced with 2 weight fractions (5) and (7.5)\% of nano clay, then rockwool was added to prepare two other castings with a volume fraction(10\%), hybridized with the previously mentioned weight fractions of nano clay. A single casting was made of solely epoxy/polyester blend for the purpose of comparison.
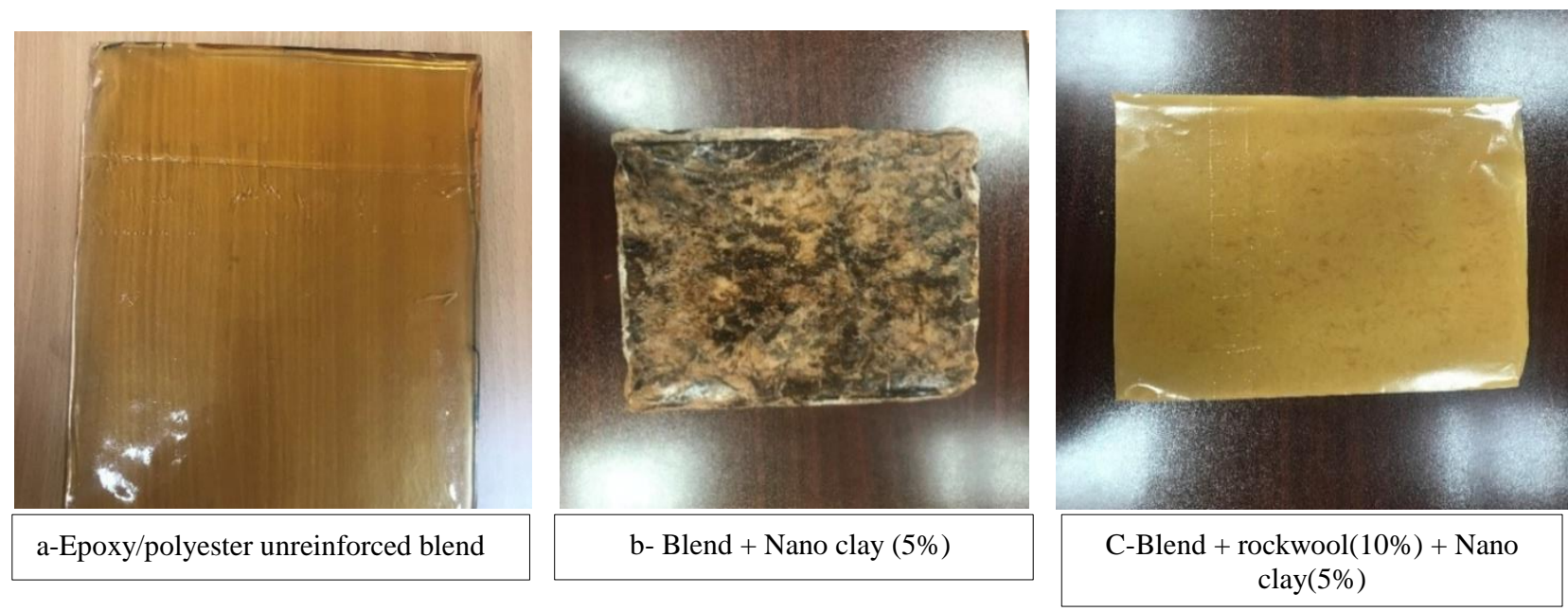

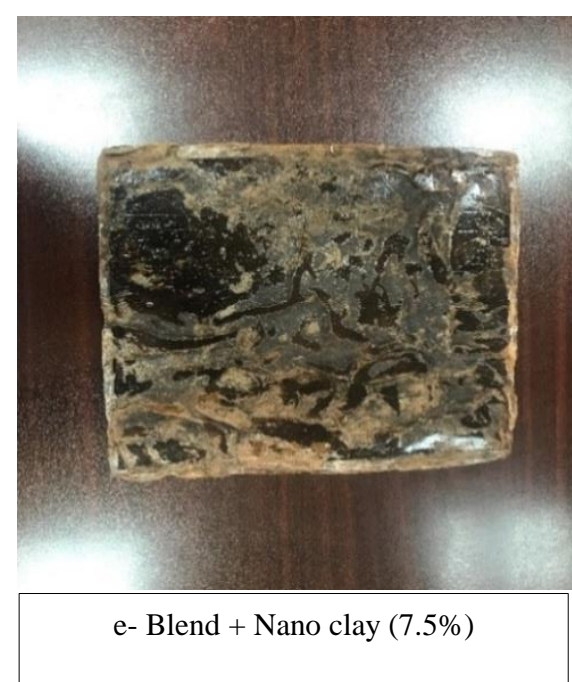

Figure1. a -e show the shape of specimen. 
All castings were left for 24 hours for primary solidification, later they were taken out of the mold and were put in a dryer for curing and stress removal. The castings are shown in Fig. 1 a -e below.

\section{The tests \\ Impact Test Instrument:}

Charpy test set, manufactured by Amityville Inc. ${ }^{\mathrm{TM}}$, was used to execute the impact strength test for the standard specimens. The set consists of a hammer that is lifted to a highest point, the left to fall freely on the specimen that is mounted horizontally on the supports. As the hammer hits the specimen, it loses its energy and the specimen fractures, the energy of fracture is read off a gauge, and then divided by the cross sectional area to get the impact strength value, according to the following relation

$$
\text { I. } \boldsymbol{S}=\frac{\boldsymbol{U}_{\boldsymbol{c}}}{\boldsymbol{A}} \ldots \ldots \ldots \ldots . .1
$$

Where, I.S. is the impact strength $\left(\mathrm{kJ} / \mathrm{m}^{2}\right)$, us: the fracture energy $(\mathrm{kJ})$ and $\mathrm{A}$ : is the cross sectional area of the sample $\left(\mathrm{m}^{2}\right)$. Fig. 2 shows the impact test samples.

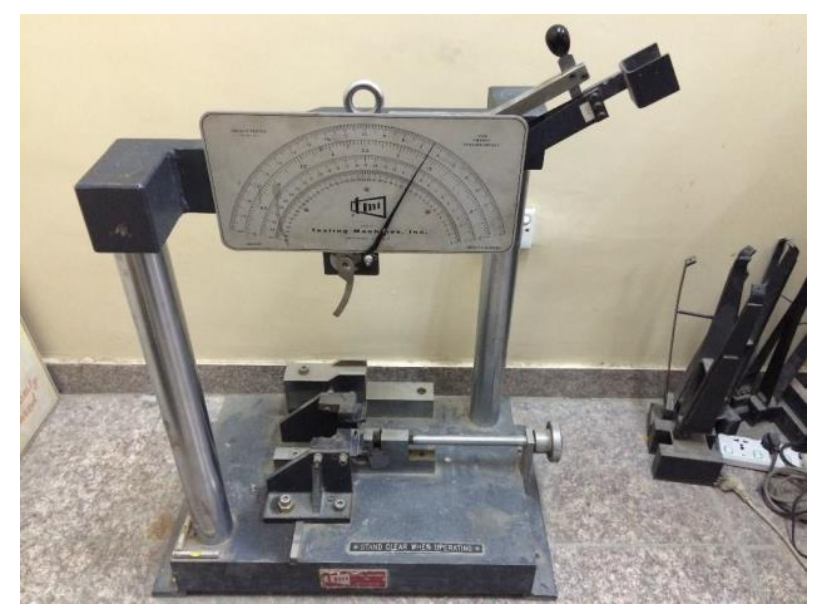

Figure 2. Impact test machine

\section{Thermal Conductivity}

Thermal conductivity of insulating materials is calculated by Lee's Disc, manufactured by (Griffin\& George/ England). The instrument consists of three copper discs $(\mathrm{A}, \mathrm{B}, \mathrm{C})$. The sample (S) is placed between the discs $\mathrm{A}$ and $\mathrm{B}$, while the heater is placed between $\mathrm{B}$ and $\mathrm{C}$ as show in Fig 1. The heater is supplied with voltage (6 volt) and the value of the electric current is $(0.25 \mathrm{~A})$. The heat transfers from the heater to the two neighboring discs then to the third disc across the sample. The temperature of the three discs (TA, TB, and TC) is measured using thermometers placed inside them. After reaching thermal equilibrium, the temperatures are recorded. The value of thermal conductivity is determined using the following equation:

$$
\begin{gathered}
\mathrm{IV}=\pi \mathrm{r}^{2} \mathrm{e}\left(T_{A}+T_{B}\right)+2 \pi \mathrm{re}\left[d_{A} T_{A}+\right. \\
\left.\mathrm{ds} \frac{1}{2}\left(T_{A}+T_{B}\right)+d_{B} T_{B}+\mathrm{dcTc}\right] \ldots 2
\end{gathered}
$$

Where:

$r$ is radius of discs.

$d_{A}$ is Thickness of first disc.

$\mathrm{d}_{\mathrm{B}}$ is Thickness of second disc.

$\mathrm{dc}$ is Thickness of third disc.

$\mathrm{e}$ is the heat that passing per second per unit area.

I is the value of current passing through the set (Ampere).

$\mathrm{V}$ is voltage (volt)

Thermal conductivity $(\mathrm{K})$ can be calculating by the following equation:

$$
\begin{gathered}
\mathbf{K}\left(T_{B}-T_{A} \mathrm{ds}\right)=\mathrm{e}\left[T_{A}+2 \mathrm{r}(\mathrm{da}+(14 \mathrm{ds})) T_{A}+\right. \\
\left.12 \operatorname{rds} T_{B}\right] \ldots \ldots . .3
\end{gathered}
$$

Where $\mathrm{r}$ : sample radius in $(\mathrm{mm}), \mathrm{T}$ : temperature rate of the thermometer mounted in the brass discs $\left({ }^{\circ} \mathrm{C}\right), \mathrm{d} A, \mathrm{~d} B, \mathrm{~d} C$ : Thicknesses of disks $\mathrm{A}, \mathrm{B}$ and $\mathrm{C}$ respectively.

The specimens were shaped as discs and the test was carried out in compliance with (ASTM D7340) the lee's disc set and the specimen can be seen in Figs.3,4. 


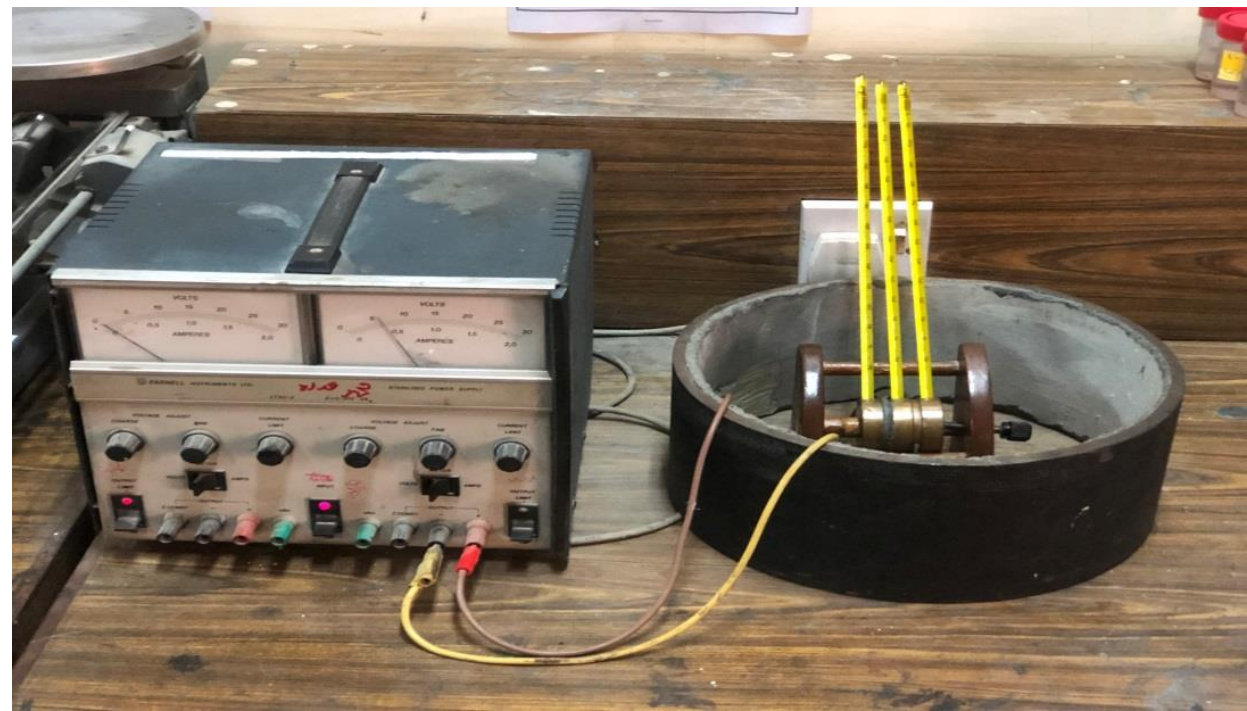

Figure 3. shows thermal conductivity measurement (Lee's Disc)

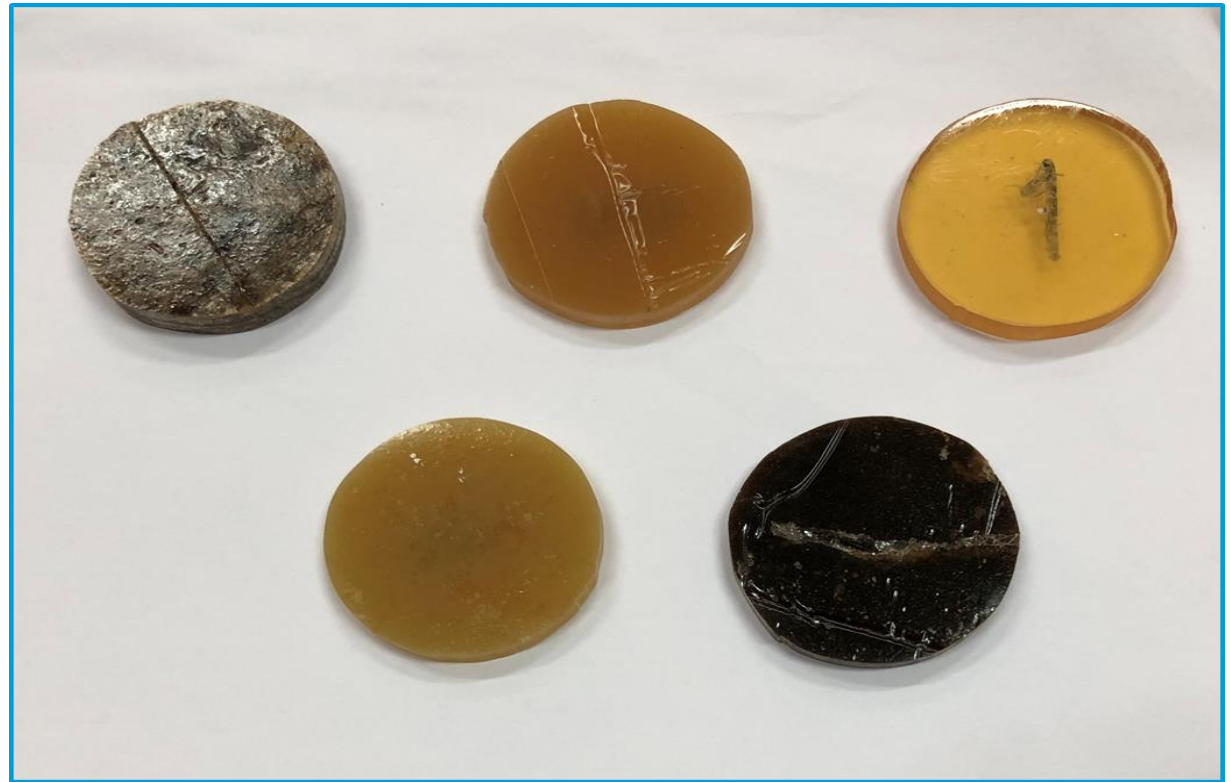

Figure 4. Thermal conductivity specimens

\section{Acoustic Insulation}

The castings were used in their original dimensions $(250 * 250) \mathrm{mm}$ to carry out acoustic insulation test. This test is according to the standard specification (ASTM E-336). Acoustic insulation test device is locally manufactured according to the specification above, in which sound waves are generated by a sound generator on one side of the box, and on the other side the loud speaker receives the generated wave, the castings are placed in the middle of the box. The intensity of sound that reaches the loudspeaker is a function of the materials ability to insulate sound, so the higher the intensity, the less the materials efficiency in insulation. The sound intensity changes as the frequency changes.

\section{Results and Discussion: \\ Thermal conductivity}

Thermal conductivity for blend (polyesterlepoxy) is $0.567 \mathrm{k}$ (w/m .c).with addition of nanoclay in the rate of $5 \%$ weight fraction a slight increase occurred in the thermal conductivity with ratio $2 \%$. by increasing addition ratio of nanoclay particles up to $7.5 \%$ weight fraction, thermal conductivity is reduced significantly from 0.589 to $0.443 \mathrm{k}(\mathrm{w} \backslash \mathrm{m} . \mathrm{c})$ the highest result of insulation was more than that showed in the work of researcher SHEN, Chaoxuan, et al.(8). When rock wool is added to the volume fraction $10 \%$ and nanoclay with weight fraction $5 \%$ to the blend (epoxylpolyester) as reinforcement, thermal conductivity drops to about $4.8 \%$ of its original value. Addition of rock wool with the same volume fraction, but with an increased nanoclay weight 
fraction $7.5 \%$ as reinforcement to the blend, reduced thermal conductivity with ratio $8.2 \%$, this agree with the results of researchers Teba M. $(9,10)$ and HAMEED(11) HSIAO, Min-Chien, et al.(12).

The result of thermal conductivity test given in Fig. 5 shows the change that occurs in thermal conductivity by adding reinforcement to the blend (epoxylpolyester).

It is known that the mechanism of the thermal transmission through insulation materials occur by vibration of atoms and transformation of this vibration to flexible quantum waves known as phonon. This mechanism occurs clearly in ceramic materials because it has a three dimensional crystal structure, thus facilitating the transition process of phonon in contrast to polymer chain that has random crystal structure and linked with each other systematically. In addition to the free size in the polymer structure, random structure and space that exists between chains, all these effects lead to a difficulty in transmission of thermal energy from side to side through polymer, taking into account the existence of interfaces between phase polymer mixture. Heat transfers as a flexible wave through the structure of the composite material, and this movement will be interrupted by the interfaces existing already between the reinforcements and the matrix, leading to wave energy loss, hence good thermal insulation. Thermal conductivity for composite reinforced with nanoclay weight fraction $7.5 \%$ was less than 0.5 (w/m .c) that shows enhance in insulation properties of the material, and that proves better thermal insulation compared with the work of Jabbar (13), whose work with (7.5\%)wt. fraction nano alumina reinforced composite showed a decreased thermal conductivity, such that it was approximately $0.8\left(\mathrm{~W} / \mathrm{m} .{ }^{\circ} \mathrm{C}\right) .(13)$

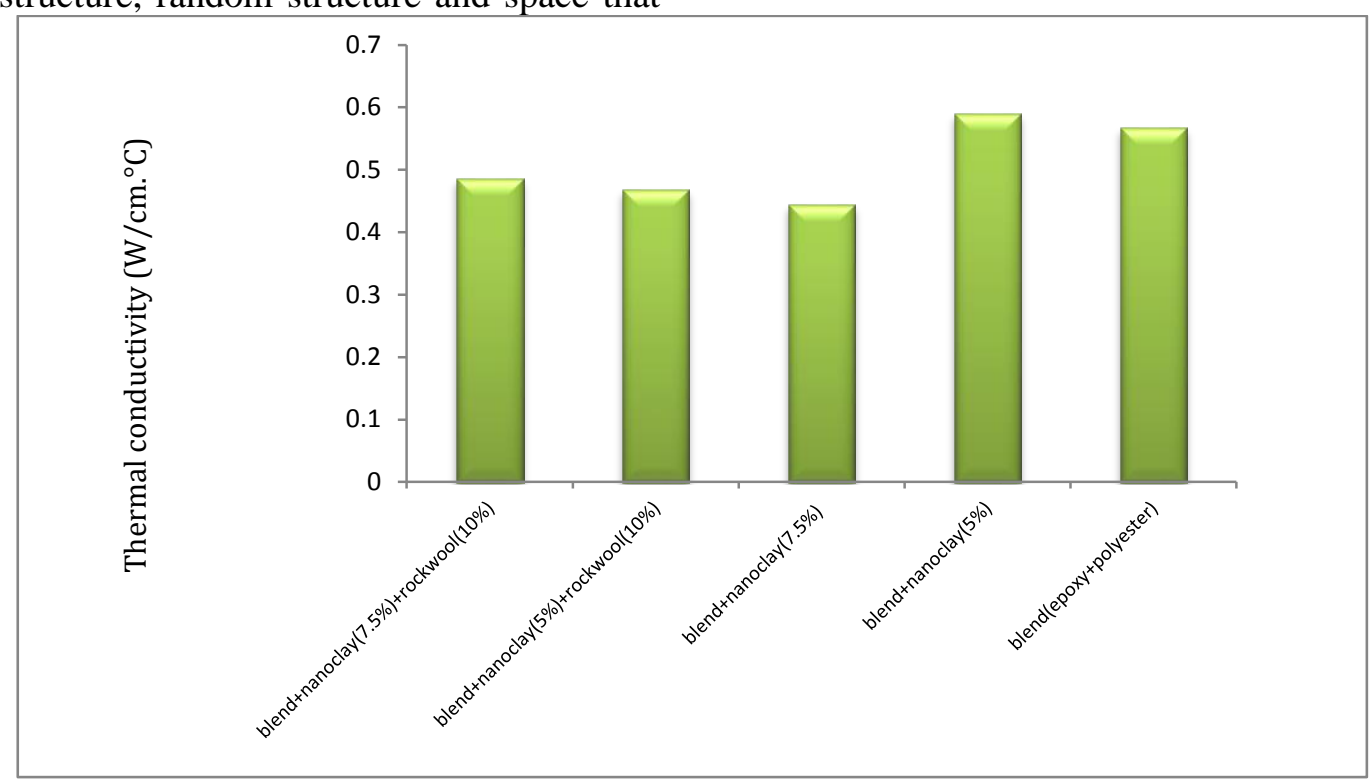

Figure 5. Thermal conductivity as a function of the addition ratio

\section{Acoustic Insulation}

Sound level is the main parameters in the determination of the acoustic insulation properties, equivalent sound absorption area and sound absorption coefficient (10).

Fig. 6 demonstrates the soundproofing properties of the blend/clay nanocomposites as a function of nanoclay contents for high frequency range. As can be seen, all samples containing nanoclay have much better sound barrier property than pure blend over high frequency tests. The best result was related to the sample containing $7.5 \mathrm{wt} \%$ of nanoclay. The sound insulation efficiency increased with increasing nanoclay content from zero to 7.5 wt $\%$, but it decreased at pure blend and that reinforced with rock wool $\mathbf{1 0 \%}$ Vf. Thus, very low loading of nanoclay in the blend matrix can dramatically improve the soundproofing property. It was observed that blend $7.5 \mathrm{wt} \%$ nanoclay had the SL (sound level) values of $101.3-99.8 \mathrm{db}$ at $10000 \mathrm{~Hz}$ which are higher than those of pure blend (14).

Sound insulation increased with $7.3 \mathrm{db}$ when nano clay was added in a weight fraction $7.5 \%$ to the composite, in comparison to the unreinforced specimen, and this shows an improvement compared to the work of researcher J. C. et.al.(7), whose research showed that nanocomposite made of (acrylonitrile butadiene styrene) as a matrix, reinforced with carbon nanotube (ABS)/CNT, enhanced the sound insulation so that it became $4.1 \mathrm{db}$ in comparison with unreinforced ABS specimen (7). 
Table 5. shows the sound intensity levels as a function of materials composition.

\begin{tabular}{cccccc}
\hline Frequency & $\begin{array}{c}\text { blend(polyeste } \\
\text { rlepoxy) }\end{array}$ & $\begin{array}{c}\text { blend+ } \\
\text { nanoclay } \mathbf{5 \%}\end{array}$ & $\begin{array}{c}\text { blend+ } \\
\text { nanoclay5\%+rock } \\
\text { wool(10\%) }\end{array}$ & $\begin{array}{c}\text { blend+nanocay(7.5\%)+r } \\
\text { ock woo(110\%) }\end{array}$ & $\begin{array}{c}\text { Blend +nano } \\
\text { clay(7.5\%) }\end{array}$ \\
\hline 100 & 107.2 & 103.5 & 101.2 & 102.4 & 99.8 \\
200 & 107.3 & 103.6 & 101.2 & 102.5 & 99.9 \\
300 & 107.3 & 103.7 & 101.3 & 102.6 & 100 \\
400 & 107.3 & 103.8 & 101.4 & 102.8 & 100 \\
500 & 107.4 & 103.9 & 101.4 & 102.9 & 100.1 \\
600 & 107.6 & 104.1 & 101.5 & 103.1 & 100.2 \\
700 & 107.6 & 104.2 & 101.5 & 103.1 & 100.3 \\
800 & 107.6 & 104.2 & 101.7 & 103.1 & 100.4 \\
900 & 107.7 & 104.3 & 101.8 & 103.2 & 100.5 \\
1000 & 107.7 & 104.4 & 101.9 & 103.3 & 100.8 \\
2000 & 108 & 104.6 & 102 & 103.6 & 100.8 \\
3000 & 108.1 & 104.7 & 102 & 103.6 & 100.9 \\
4000 & 108.2 & 104.7 & 102.1 & 103.7 & 100.9 \\
5000 & 108.2 & 104.8 & 102.1 & 103.8 & 101.1 \\
6000 & 108.4 & 104.9 & 102.2 & 103.8 & 101.2 \\
7000 & 108.3 & 104.9 & 102.3 & 104.1 & 101.3 \\
8000 & 108.5 & 105 & 102.4 & 104.2 & 104.3 \\
9000 & 108.6 & 105.1 & 102.5 & 104.3 & \\
10000 & 108.7 & 105.1 & 102.6 & & \\
\hline
\end{tabular}

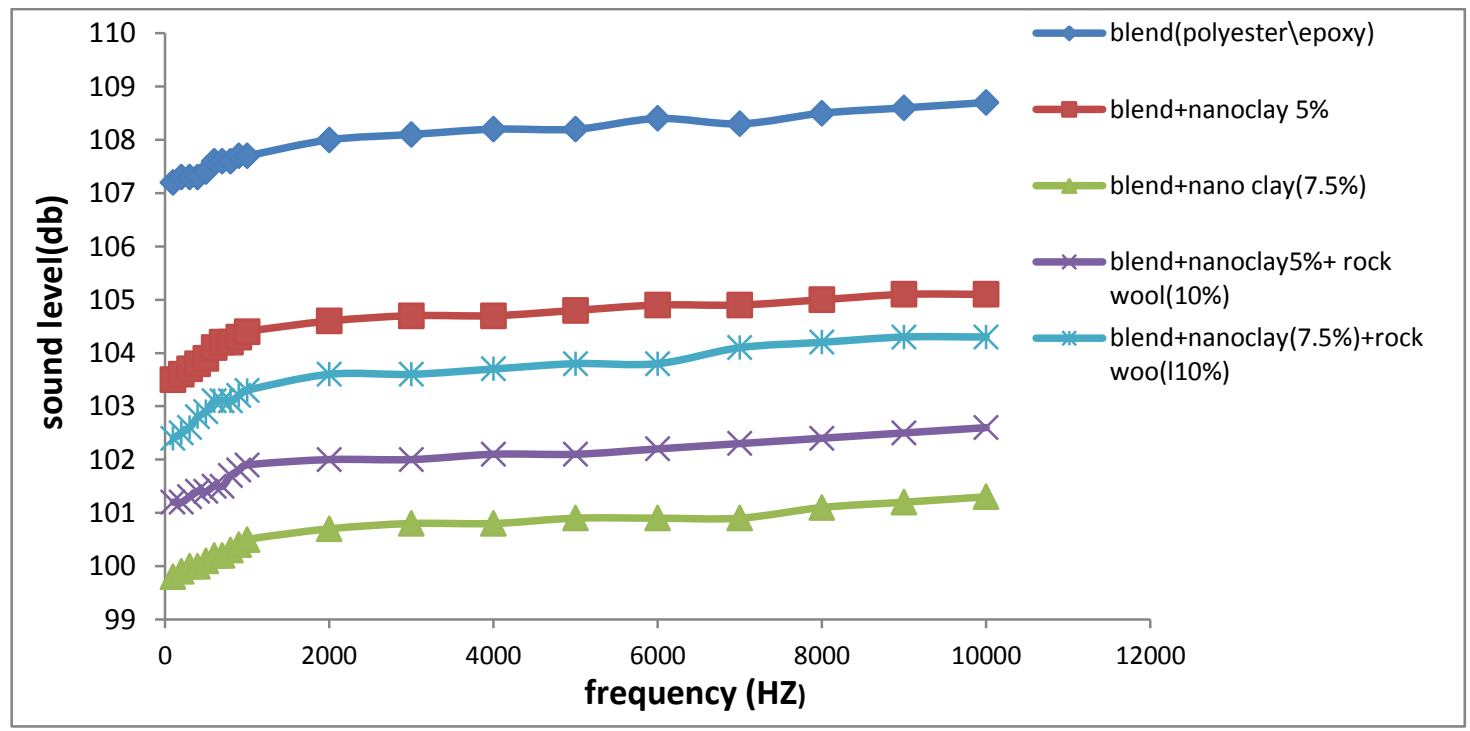

Figure 6. the relation between sound level and frequency

\section{Conclusion:}

Epoxy and polyester can be mixed in different percentages without visible phase segregation, however, optimum mixing ratio can be decided upon carrying out the impact test, through which the specimen giving the highest value can be chosen to work with through the results It turns out that the best added ratio of nanoclay to the blend (polyester+ epoxy) is $7.5 \%$ weight fraction.The prepared nanocomposite has low thermal conductivity, thus better thermal insulation, and the addition of hybrid reinforcement of nanoclay and rockwool increase thermal insulation. The results of sound insulation test prove that the mixture is reinforced with rockwool and nanoclay reaches the highest value of sound insulation.

\section{Authors' declaration:}

- Conflicts of Interest: None.

- We hereby confirm that all the Figures and Tables in the manuscript are mine ours. Besides, the Figures and images, which are not mine ours, have been given the permission for republication attached with the manuscript.

- Ethical Clearance: The project was approved by the local ethical committee in University of Technology. 


\section{References}

1. Mohamed A, Mobarak Y. Novel nanocomposite insulation materials for the enhancing performance of power cables. In 21st International Conference on Electricity Distribution, France, Frankfurt 2011.

2. Ahmadi S, Nassiri P, Ghasemi I, Esmaeilpoor M R M. Sound transmission loss through nanoclayreinforced polymers. Iran Polym J.2015; 24(8): 641649; DOI 10.1007/s13726-015-0353.

3. Ebadi-Dehaghani, Hassan, Monireh Nazempour. Thermal conductivity of nanoparticles filled polymers. Smart nanoparticles technology. Tech, 2012.

4. Chen H, Ginzburg VV, Yang J, Yang Y, Liu W, Huang Y, et al. Thermal conductivity of polymerbased composites: Fundamentals and applications. Prog Polym Sci. 2016. 59:41-85.

5. Kaya, Gulcihan G, Elif Y, Huseyin D. Sustainable nanocomposites of epoxy and silica xerogel synthesized from corn stalk ash: Enhanced thermal and acoustic insulation performance. Elsevier $\mathbf{J}$ Compos Part B. 1 October 2018; 150: 1-6

6. Buratti C, Moretti E, Belloni E, Agosti F. Thermal and acoustic performance evaluation of new basalt fiber insulation panels for buildings. Elsevier J Energ Pro a. 2015; 78: $303-308$.

7. Lee J C, Hong Y S, Nan R G, Jang M K, Lee C S, Ahn S H et.al. J. 2008. Soundproofing effect of nano particle reinforced polymer composites. MeSH .
2008; 22: 1468 1474; DOI 10.1007/s12206-0080419-4.

8. Shen C, Wang H, Zhang T, Zeng Y. Silica coating onto graphene for improving thermal conductivity and electrical insulation of graphene/ polydimethylsiloxane nanocomposites. J of Materials Sci. \& Technology.2019;35(1), 36-43.

9. Teba M. Study the Effect of Nano Materials on the Physical Properties of Epoxy blend, MS.c. Thesis, Department of Applied Science, University of Technology 2016.

10. Hamood I A .Impact Behaviour for Epoxy Blends and Composites. MS.c. Thesis, Department of Applied Science, University of Technology 2009.

11. Hameed, Awham M, Talib A A. Using the plastic wastes in fabrication of composite materials for different applications. Iraqi J of Physics, 2018, 16.36: 123-133.

12. Hsiao M C, Ma C C M, Chiang J C, Ho K K, Chou T $\mathrm{Y}, \mathrm{Xie} \mathrm{X}$, et.al. Thermally conductive and electrically insulating epoxy nanocomposites with thermally reduced graphene oxide-silica hybrid nanosheets. Nanoscale. 2013; 5(13), 5863-5871.

13. Huda J. study the tensile strength of polymer composite reinforced with carbon molecular. journal of the college of basic education. 2015; 6-1. 21(89): 1

14. Sally A K, Mohammed M. Investigation of tensile, physical and microstructure properties for chemically treated sawdust/UPE composites. MS. C. Thesis. Iraq: University of Technology; 2015.

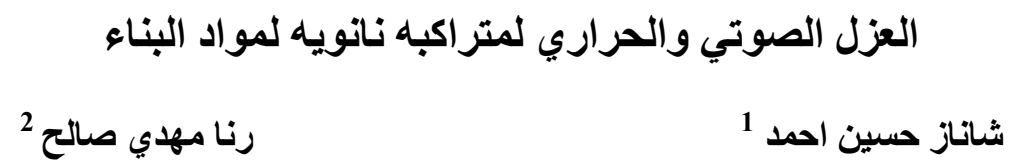

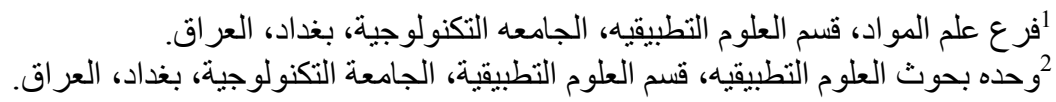

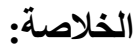

يهذف البحث الى تعزيز خصائص العزل الحراري و الصوتي لمادة متراكبة بوليمرية، مصنعة من خليط من (الأيبوكسي+بولي

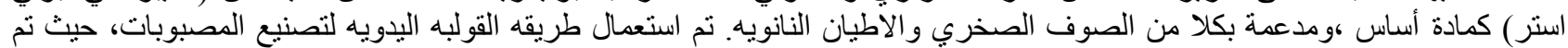

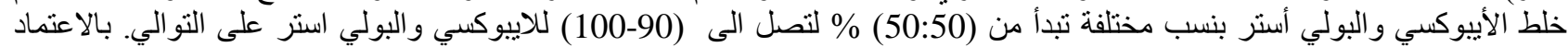

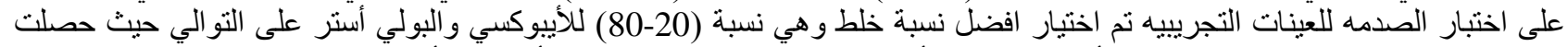

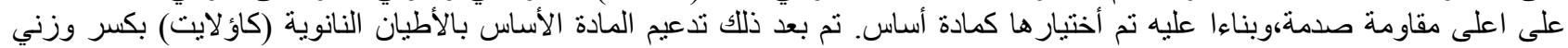

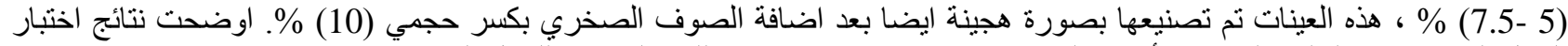

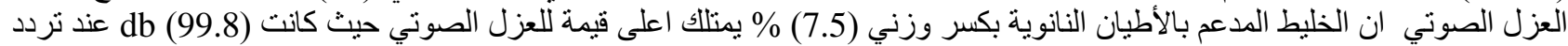

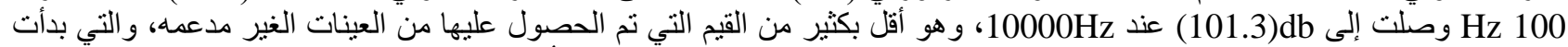

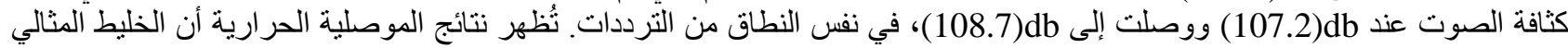

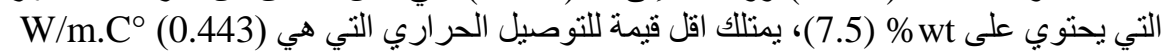
الكلمات المفتاحيه:عزل صوتي، اطيان ناويه، متر اكبه نانويه، خليط بوليمري، عزل حر اري 